\title{
Geological Sample Preparation Evaluations by EBSD Pattern Quality
}

\author{
G. Alvares*, L. Lagoeiro**, P. Barbosa** \\ * Departamento de Engenharia Metalúrgia e de Materiais, Universidade Federal de Ouro Preto, \\ Ouro Preto, MG, 35400-000, Brazil. \\ ** Departamento de Geologia, Universidade Federal de Ouro Preto, Ouro Preto, MG, 35400-000 \\ Brazil.
}

The EBSD (Electron Backscatter Difraction) technique is commonly used to microanalytical measurements as texture and phase distributions in materials and earth sciences [1]. The patterns are formed and collected within the first tens of nanometer of material surfaces and therefore damagefree specimens surfaces are required.

The Pattern "quality" (PQ) calculations, performed by the EBSD systems, give a qualitative idea of how good the sample preparation is. In addition to the strain level in the sample, these analyses are also highly sensitive to the crystallographic orientation and structure, phase density and EBSD system settings [2], what means that these factors have to be carefully controlled in order to use this tool as a sample-surface-conditions measurement.

From pattern "quality" indices, this work aims to evaluate the sample surface conditions after some of the procedures necessary for geological samples preparation was carried out. The specimen used was a naturally deformed rock composed of quartz and sulfides (pyrite and arsenopyrite).

The rock was cut in a low speed saw (Isoment-Buehler) with high-density diamond cut-off wheel. In the first procedure, the sample was grinded with diamond discs of 45 and $15 \mu \mathrm{m}$, using water as cooler agent, with loads of $5 \mathrm{lb}$ load and $30 \mathrm{rpm}$, until an even surface was reached. After that, the sample was mechanically polished with diamond pastes of 9 down to $0.25 \mu \mathrm{m}$ for 30 minutes each. Both grinding and mechanical polishing steps were checked in an optical microscope. The last step was the lapping procedure in a colloidal silica $(20 \mathrm{~nm})$ for 2 and $4 \mathrm{~h}$. In the second procedure, the sample was grinded from 240 down to 1200 grit $\mathrm{SiC}$ abrasive papers, water as cooler agent, under $5 \mathrm{lb}$ load and $30 \mathrm{rpm}$. The mechanically polish step was the same as that applied in the first case, except that the lapping procedure with colloidal silica was accomplished in a vibratory polisher in the same time intervals.

For the first procedure, 2 hours of lapping processes with colloidal silica show a better indexing rate (78.72 to $76.71 \%$ ). The sulfides were well-polished which was not enough the quartz in sample. The better Pattern "quality" index for quartz was achieved after 4 hours of lapping in colloidal silica. This was an excessive time for the pyrite and arsenopyrite causing a surface damage to them. The second lapping procedure took 2 and 4 hours leading to good index rates $(90.15$ and $86.71 \%)$, it must be accounted for less aggressive grinding steps. The Band Contrast Maps 3 and 4 are similar, but after 4-hours lapping, some induced noise in pattern for quartz and pyrite can be observed (Fig.3 and 4, arrows), what could explain decrease in the indexing rate. The first procedure conducted in 2 hours of lapping process reach great results for polish sulfides, though diamond discs have been used, what shows that this kind of abrasive can work good even with low hardness materials. On the 
other hand, the second lapping procedure of 2 hours resulted in homogeneous and best polishing surfaces for sulfides and quartz samples.

Thus, this work is current underway to require the influence of each kind and size of abrasive during the grinding stage. The mechanical polishing steps are also being evaluated.

\section{References}

[1] M.M. Nowell et al., Microsc. Microanal. 15 (suppl 2) (2009) 780.

[2] S.D. Stizman, G. Nolze, M.M. Nowell, Microsc. Microanal. 16 (suppl 2) (2010)

[3] This research was supported by the FAPEMIG.
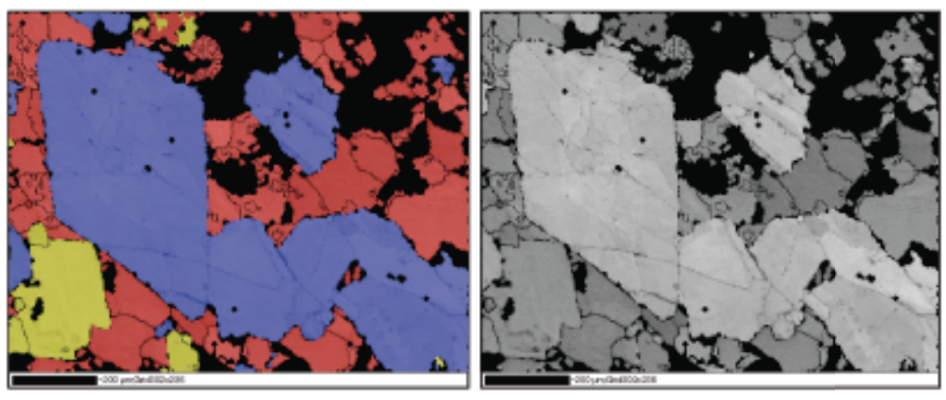

Figure 1: (a) Phase Colors Map: Blue Arsenopyrite $43.63 \%$, Red Quartz $28.48 \%$ and Yellow Pyrite $6.61 \%$; (b) Band Contrast Map showing the pattern "quality" (PQ) index in 0-255 white-black scale. In avarage Arsenopyrite: $163.210 \pm 17.261$

Pyrite: 119.400土13.686; Quartz: 115.580 15.088 ;
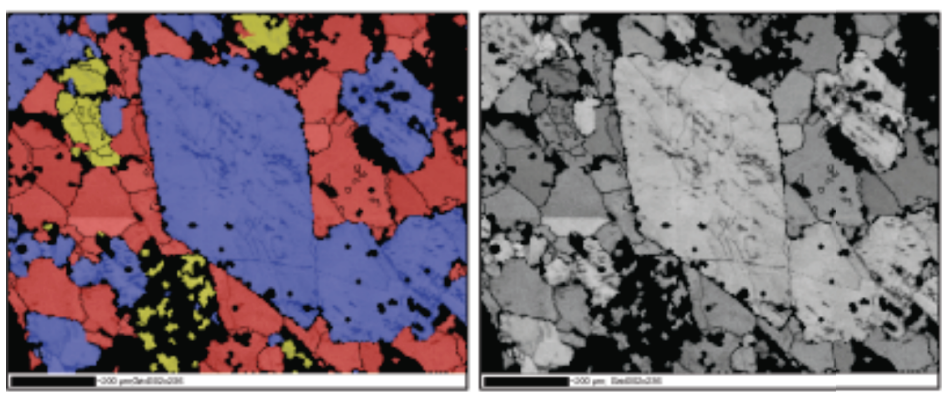

Index rate: $78.72 \%$.
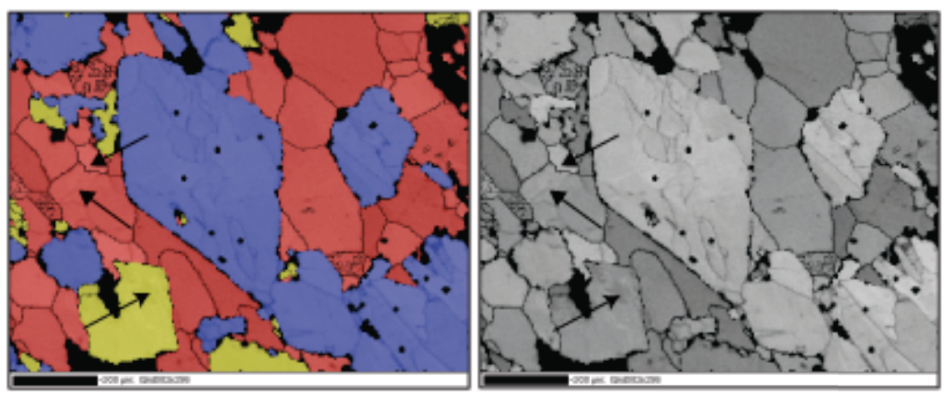

Figure 2: (a) Phase Colors Map: Blue Arsenopyrite $40.78 \%$, Red Quartz $31.64 \%$ and Yellow Pyrite 4.29\%; (b) Band Contrast Map showing the pattern "quality" (PQ) index in 0-255 white-black scale. In average Arsenopyrite: $149.910 \pm 29.474$

Pyrite: $100.770 \pm 19.696$; Quartz: 116.680 18.243 ; Index rate: $76,71 \%$.
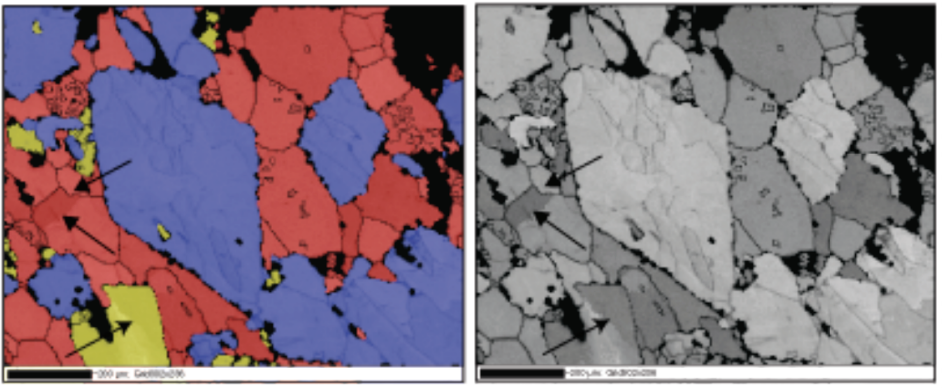

Figure 3: (a) Phase Colors Map: Blue Arsenopyrite $40.08 \%$, Red Quartz $42.45 \%$ and Yellow Pyrite 7.62\%; (b) Band Contrast Map showing the pattern "quality" (PQ) index in 0-255 white-black scale. In average Arsenopyrite: $155.310 \pm 20.590$

Pyrite: 113.220 \pm 17.238 ; Quartz: 119.690 \pm 18.135 ;

Index rate: $90,15 \%$.

Figure 4: (a) Phase Colors Map: Blue Arsenopyrite 42.70\%, Red Quartz 39.05\% and Yellow Pyrite $4.96 \%$; (b) Band Contrast Map showing the pattern "quality" (PQ) index in 0-255 white-gray scale. In average Arsenopyrite: $157.270 \pm 19.582$

Pyrite: $107.750 \pm 19.426$; Quartz: 117.320 16.951 ; Index rate: $86.71 \%$. 